\title{
AS TVS LEGISLATIVAS COMO INSTRUMENTO DE PROMOÇÃO DO PLURALISMO E DA DIVERSIDADE ${ }^{1}$
}

Fernando Oliveira Paulino ${ }^{2}$

Resumo: O autor discute o papel das emissoras legislativas de televisão, a partir da experiência dos 20 anos da TV Câmara, no contexto democrático brasileiro, com ênfase para o papel dessas emissoras no debate público baseado no pluralismo de ideias e opiniões.

Palavras-chave: TVs legislativas; Comunicação Pública; TV Câmara; Liberdade de expressão; Pluralismo.

Abstract: The author of paper discussed by legislatives TV stations, based on the experience of 20 years of TV Câmara, in the Brazilian democratic context, highlighting the role of those broadcasters in the public debate based on pluralism of ideas and opinions.

Key words: Legislative TVs; Public Communication; TV Câmara; Freedom of expression; Pluralism.

Resumen: El autor discute el papel de las emisoras legislativas de televisión, a partir de la experiencia de 20 años de la televisión de la Cámara de Diputados, con énfasis en el papel de estas emisoras en el debate público basado en el pluralismo de ideas y opiniones

Palabras-clave: Televisiones legislativas; Comunicação Pública; TV Câmara; Libertad de expresión; Pluralismo.

\section{Introdução}

É fundamental levar em conta que as experiências de canais legislativos foram estabelecidas no Brasil com o amparo da Lei $\mathrm{n}^{\circ}$ 8.977, de 1995, mais conhecida como Lei do Cabo. A norma resultou de um processo histórico com debates e ações que contaram com o esforço significativo de pesquisadores, professores, profissionais, estudantes de comunicação e demais pessoas interessadas em reflexões e práticas ligadas ao direito à comunicação, à liberdade de expressão, à diversidade de opiniões e à comunicação pública.

\footnotetext{
${ }^{1}$ Conferência do autor durante o Seminário Internacional 20 anos da TV Câmara, realizado em junho de 2018.

${ }^{2}$ Doutor e mestre em Comunicação. Professor e Diretor da Faculdade de Comunicação da UnB. Pesquisador do Laboratório de Políticas de Comunicação (LaPCom-UnB) e do Projeto Comunicação Comunitária e Cidadania (CNPq). Diretor de Relações Internacionais da Associação Latino-Americana de Investigadores da Comunicação. E-mail: fopaulino@gmail.com
} 
Antes, durante e depois da Assembleia Nacional Constituinte, a Câmara dos Deputados e o Senado Federal acolheram debates e mobilizações que tiveram a importante participação de jornalistas, majoritariamente representados pela Federação Nacional dos Jornalistas (FENAJ); de radialistas atuantes na Federação dos Radialistas (FITERT); de pessoas ligadas à Frente, posteriormente, denominada Fórum Nacional pela Democratização da Comunicação; e também de professores e estudantes universitários, com um histórico acumulado desde os anos $1970 \mathrm{em}$ ações de promoção ao direito à informação e à comunicação, compreendendo a tais direitos como imprescindíveis para a democracia.

Neste ano de 2018 - vale a pena esse registro - existem relevantes efemérides. Celebram-se os 40 anos de criação da Comissão Internacional para Estudo dos Problemas da Comunicação, conhecida internacionalmente como Comissão MacBride. Instituída pela Unesco, a Comissão produziu um Relatório seminal cujo título em português é "Um Mundo e Muitas Vozes - Comunicação e Informação na nossa época". As versões em inglês, em francês e em espanhol deste relatório está disponível na Internet ${ }^{3}$.

Muitos dos argumentos sistematizados no Relatório podem ser aproximados a esforços que a TV Câmara tem desenvolvido em termos de fomentar a diversidade de opiniões e também criar condições para a circulação livre de informação, comunicação e cultura. Em síntese, o relatório da Comissão Mac Bride apresenta instrumentos e reflexões associados à compreensão de que não somente temos o direito de solicitar e receber informações, mas também de produzir e distribuir conteúdos, algo que sustenta as bases do direito à comunicação. A aplicação desse princípio, possivelmente, é um dos desafios principais que os canais legislativos têm, não só o de dar voz aos representantes eleitos na missão de representação política — volto ao tema abaixo — , mas também o de oferecer espaço para expressão de representantes e representados(as) em suas posições, opiniões e atividades desenvolvidas em âmbito sociocultural.

\section{O legado da Lei do Cabo}

A Lei do Cabo determinou a criação não só dos canais legislativos, mas também de outros canais básicos - assim chamados na lei — de utilização gratuita. Acho que vale a pena citar um trecho da norma porque ela estabelece um reforço no "DNA público" dos canais legislativos, especialmente os sediados na capital federal, e também serve de referência para os demais canais legislativos pelo país, mesmo em situações de crise orçamentária e com possíveis dificuldades de gestão.

\footnotetext{
${ }^{3}$ Versão em espanhol disponível em: https://unesdoc.unesco.org/notice?id =p::usmarcdef_0000040066_spa.
} 
A lei estabeleceu a criação do seguinte:

\begin{abstract}
Art. 23
b) um canal legislativo municipal/estadual, reservado para o uso compartilhado entre as Câmaras de Vereadores localizadas nos Municípios da área de prestação do serviço — do cabo, mas que pode ser expandido porque sabemos que ainda há restrição no acesso à TV por assinatura no País - e a Assembleia Legislativa do respectivo Estado, sendo o canal voltado para a documentação dos trabalhos parlamentares, especialmente a transmissão ao vivo das sessões.
\end{abstract}

Quando da elaboração da norma, houve essa preocupação com a transmissão das sessões legislativas, pauta essencial para justificar a existência dos canais ligados às Câmaras, Assembleias e ao Congresso, como pode ser observado no trecho da Lei do cabo apresentada abaixo. Por outro lado, de forma associada a tal atividade precípua e de maneira relacionda ao tema deste Seminário, é importante perceber as possibilidades e experiências nas quais os milhares de municípios brasileiros que tem acesso ao canal da TV Câmara, também criem, a exemplo do que foi anunciado no relatório da Comissão MacBride, canais de produção, distribuição e acesso aos seus conteúdos legislativos e ao cotidiano das municipalidades utilizando práticas de radiodifusão e Internet. A lei também estabeleceu o seguinte:

c) um canal reservado para a Câmara dos Deputados, para a documentação dos trabalhos, especialmente a transmissão ao vivo das sessões;

d) um canal reservado para o Senado Federal;

e) um canal universitário, reservado para uso compartilhado entre as universidades localizadas no Município ou nos Municípios da área de prestação de serviços.

No que se refere aos canais universitários, também há um déficit normativo e de políticas públicas para garantir que as instituições de educação superior consigam encontrar maneiras de estabelecer e manter tais canais e, com isso, façam deles um espaço de popularização, de diálogo entre universidade e sociedade e de divulgação do conhecimento científico. Além dos canais universitários, existem outras pendências entre o estabelecido pela norma e a realidade, tais como:

f) um canal educativo-cultural, reservado para a utilização pelos órgãos que tratam da educação e da cultura no Governo Federal e nos Governos Estadual e Municipal com jurisdição sobre a área de prestação de serviços.

g) um canal comunitário aberto para utilização livre por entidades não governamentais e sem fins lucrativos.

Muitos canais comunitários se estabeleceram, mas infelizmente por um lado existem poucos estímulos para suas existências. Por outro, a determinação da norma contribuiu para um debate bem interessante de como os canais comunitários estão previstos e se constituem, a duras penas, na TV paga, mas não estão na TV aberta, o que não deixa de ser uma espécie de contradição, ainda pendente não só de debate legislativo, mas de práticas associadas ao Executivo e ao Judiciário. Em relação ao Judiciário, a Lei do Cabo também determinou a criação de: 
h) um canal reservado ao Supremo Tribunal Federal para a divulgação dos atos do Poder Judiciário e dos serviços essenciais à Justiça.

Neste aspecto, a TV Justiça tem desenvolvido um trabalho importante e inovador que pode ser medido, dentre outros crítérios, pelo impacto das transmissões nas atividades desenvolvidas pelos atores, digamos assim, veiculados, especialmente, no caso da TV Justiça, os membros do Supremo Tribunal Federal (STF).

Faço referências diretas à Lei do Cabo, porque tal norma ao herdar bases do Projeto de Lei de Mídia Democrática, que foi uma das principais bases de discussão durante o período constitucional, serviu para uma reflexão que expandiu essa perspectiva de um "DNA público" e não apenas institucional para os canais legislativos. Tal característica não deixa de ser uma marca importante no comparativo do Brasil com outras experiências internacionais.

\section{Experiências internacionais}

Se analisarmos, por exemplo, a experiência do Reino Unido, com a BBC e seu canal específico para o Parlamento de maneira comparada com as práticas brasileiras, verificaremos uma programação especialmente da TV Câmara e da TV Senado traz um conteúdo de expressão cultural com uma preocupação de dar espaço para o maior número possível de tendências políticas, culturais e artísticas incluindo gêneros mais assentados às culturais nacionais e fenônemos mais recentes que, modestamente, creio que devam ter seu lugar, até porque existem certos represamentos de algumas manifestações. Um exemplo disso pode ser a necessidade de espaço para práticas culturais ligadas ao rap e/ou ao rock. Poderíamos ter até um debate associado a isso, ainda mais em Brasília, cidade com importantes expressões culturais ligadas a estes dois fenômenos. Agora, claro, a programação de canais públicos precisa se basear em condições técnicas e bases com decisões institucionais que têm condições de evitar, ou ao menos diminuir, uma programação com conteúdo personalista.

Assim sendo, avalio que a experiência de cuidado e de atenção a expressões culturais faz da programação da TV Câmara e da TV Senado algo que as diferencia positivamente de experiências de países como Reino Unido e EUA, com pouco espaço ou nenhum em expressões culturais, como nós temos na experiência brasileira macro, não necessariamente nas experiências brasileiras estaduais e municipais.

As experiências internacionais também podem nos ser úteis em função de canais no exterior estarem diversificando suas experiências de produção, distribuição e acesso a conteúdos em muitas experiências legislativas como resultado não apenas do advento da TV por assinatura, mas especialmente da Internet. A Rede Mundial de Computadores tem feito com que mesmo países que não tinham os canais e abrangência nacional, como existe no Brasil, estabeleçam canais via Youtube para a transmissão, para o registro das sessões. O Parlamento da Argentina tem feito 
um trabalho interessante nessa área e também pode servir de referência para as reflexões e práticas no Brasil.

E, claro, há outro nó importante no âmbito internacional e nacional que está associado a presença dos canais públicos do Poder Legislativo nas mídias sociais. Em outras palavras, como fazer das mídias sociais espaços e ambientes de difusão de conteúdos públicos, não apenas institucionais, desenvolvidos por instâncias legislativas? Esse também é um tema bastante fascinante. As experiências no âmbito macro, internacional, e também no âmbito micro, municipal, podem servir de referência interessante e permanente para o aprimoramento das práticas da TV Câmara e dos outros canais desenvolvidos aqui pela Secretaria de Comunicação da Câmara dos Deputados.

\section{Testemunho}

Para frisar outra parte da apresentação de reflexões sobre o conteúdo desenvolvido e a relevância dos canais legislativos, eu queria pedir licença para dar um testemunho pessoal não só como telespectador e fonte da TV Câmara, mas também como ilustração do que me parece ser o diferencial do veículos de comunicação do Parlamento em relação a outros canais.

Muito possivelmente a maior parte das pessoas que leram e vão ler este texto não tem ideia de onde estavam no dia 4 de fevereiro de 2010. Eu sei que esta é uma pergunta absurda, mas, de repente, alguém teve uma experiência inesquecível, como estar na sala de parto ou no aniversário de alguém, e com isso se lembrar da data de 4/2/10 com mais facilidade. Na data citada acima, aconteceu algo inesquecível para mim. Peço desculpas por encerrar minha contribuição com um testemunho individual, mas entendo que tal iniciativa tem a ver com o espírito do seminário que deu estímulo para esta apresentação. Para dar pistas que estimulem as pessoas a se localizarem no tempo e no espaço, informo que na véspera desse dia 4/2/10, ou seja, no dia 3 de fevereiro, o Avatar, filme de James Cameron, assumiu a posição de maior bilheteria do cinema, que era ocupada pelo Titanic. Falo isso só para vocês se lembrarem mais ou menos do contexto do período. Dias depois, em $1^{\circ}$ de março, Pepe Mujica assumiu a Presidência do Uruguai. Já em Brasília, na Câmara dos Deputados, em 4/2/10 ocorreu uma Audiência Pública para se debater o 3.o Programa Nacional de Direitos Humanos ${ }^{4}$.

Por que faço referência a realização da Audiência? É porque, por ter participado da Comissão Organizadora da 1.a Conferência Nacional de Comunicação, fui convidado a participar da Audiência em momento no qual havia uma tensão muito grande porque dias antes, com a

\footnotetext{
4 Mais informações sobre o evento estão disponíveis em: http://www2.camara.leg.br/camaranoticias/noticias/DIREITOS-HUMANOS/145032-PLENARIO-PODERADISCUTIR-DIREITOS-HUMANOS-EM-COMISSAO-GERAL.html
} 
divulgação do 3.o Programa Nacional de Direitos Humanos (PNDH), começou a surgir a ideia de que o documento poderia se constituir um atentado à liberdade de expressão no Brasil.

Certamente, as referências acima podem ter ajudado a promover a lembrança daqueles(as) que acompanharam este período, momento no qual houve editoriais e mobilizações criticando a considerada por eles tentação autoritária do Governo Federal de então, que tinha organizado uma Conferência Nacional, 27 Conferências Estaduais e eventos municipais ou com públicos específicos que geraram muitas propostas que estimulavam maior circulação de informações no Brasil e dialogavam com a proposta do PNDH de haver um monitoramento de conteúdos que eram veiculados e que transgredissem direitos humanos.

A relevância de compartilhar as informações acima neste texto são relacionadas ao fato de que ao chegar para participar da Audiência Pública, deparar-me com um corredor repleto de câmeras e microfones - muitos equipamentos ali presentes para conseguir alguns depoimentos que confirmassem ideias pré-estabelecidas de que o governo federal buscava realizar atentados à liberdade de expressão no Brasil. Na condição de especialista, ao chegar às proximidades do espaço no qual seria a Audiência, fui arguido - pela primeira vez ou talvez pela última, não sei — por cerca de 20 jornalistas. A pergunta básica foi: “- Professor, não é verdade que o atual Governo quer restringir e censurar a mídia no Brasil e que o Programa Nacional de Direitos Humanos é um atentado à liberdade de expressão?”

Confesso que naquele momento, a exemplo dos dilemas vividos pelo personagem na cena final de A Última Tentação de Cristo ${ }^{5}$, também passou um filme na minha cabeça. E, diante dos microfones, eu confesso - e não sei se alguém aqui já teve essa sensação - eu pensei: “- Se eu falar que sim, que o atual governo quer restringir e censurar a mídia, eu vou aparecer num importante telejornal de uma importante rede de televisão. Talvez pessoas da minha família e amigos vão assistir e vão ter uma referência televisiva sobre mim e, com isso, poderia até ganhar outro status". Sério, juro que eu pensei nisso num átimo de segundo, como diriam os portugueses. "Imaginei até que a partir de uma resposta com essa, talvez os meus livros ganhassem mais repercussão"

Ao mesmo tempo, a minha consciência, meu "grilo falante" apareceu - tudo isso num intervalo de poucos segundos -, e comecei a pensar o seguinte: “- Poxa, espera aí, deixe-me ver se eu entendi o que está acontecendo". Vale ressaltar que toda a situação acima ocorreu no dia 4 de fevereiro. A etapa nacional da Conferência Nacional de Comunicação aconteceu na primeira quinzena de dezembro, menos de três semanas antes. Diante disso, me lembrei que "Grande parte desses microfones que estão aqui não participaram da Conferência Nacional de Comunicação. Há dificuldade de oferecer espaço para o contraditório e para a diversidade de conteúdos, etc. Agora

${ }^{5}$ Filme dirigido por Martin Scorcese em 1988, baseado na obra de Níkos Kazantzákis. 
querem essa confirmação." Eu segui, então, o grilo falante e comecei a dizer o seguinte: "Olha, veja bem, na verdade..." Cada expressão que eu utilizava nesse sentido significava um microfone que caía da entrevista na minha frente no corredor. No final, só sobraram os instrumentos do NBR e da TV Brasil. De forma que - e agora vocês vão entender por que eu contei essa historinha , quando eu terminei de dar respostas ou estava perto de terminar, de desenvolver a ideia, sobraram apenas dois microfones para me ouvir: o da TV Câmara e o da Rádio Câmara. Isso é bastante significativo do ponto de vista da necessidade que essas emissoras têm de propagar o contraditório e a diversidade de conteúdos.

Isso demonstra a relevância de uma canais plurais, na qual cabem não só todos os partidos, todos os representantes, mas também a ideia de que esse balanço, dentre outras produções científicas, está presente, por exemplo, na tese de Mariana Martins Comunicação pública: função e legitimação das tevês legislativas federais, que traz o seguinte trecho:

Partiu-se da hipótese inicial, que foi comprovada por esta tese de que a diversidade de interesses e poderes políticos presentes no Poder Legislativo abriria também espaços para uma maior autonomia relativa dos veículos de comunicação deste Poder, favorecendo mecanismos de controle interno e externo e possibilitando espaços mais propícios à realização dos princípios da comunicação pública.

Isso me faz perceber que, embora haja uma diferença significativa entre princípios editoriais jornalísticos relacionados a experiências privadas, especialmente num país como o nosso, e experiências públicas, os veículos de comunicação da Câmara e do Senado têm obtido mais condições de proporcionar um relato verdadeiro, complexo e inteligente dos acontecimentos diários, dentro de um contexto que lhes ofereça significado, constituindo-se a TV Câmara, a exemplo de outro documento importante publicado em 1947, nos Estados Unidos, pela Comissão Hutchins, intitulado Uma imprensa livre e responsável — sem tradução ainda em português —, um fórum para intercâmbio de comentários e críticas. A meu ver, esse é um exemplo bem significativo. Assim como uma ferrovia não pode se recusar a transportar qualquer passageiro que tenha comprado um bilhete, uma instituição de comunicação, especialmente legislativa, não pode recusar espaço em seu noticiário para divulgar as ações ou pontos de vista de grupos ou indivíduos que tenham sido criticados.

\section{Conclusão}

Parece-me que as experiências locais, nacionais e internacionais são muito importantes para serem estudadas, mas essa preocupação com a programação cultural e a diversidade, desenvolvidas pela TV Câmara, pode servir de referência para outras ações, materializando-se como algo que consolida essa ideia e essa prática de comunicação pública, carecendo de alguns instrumentos - e gostaria de citá-los aqui nesse curto tempo que que eu ainda tenho - que passam pela garantia funcional das condições de trabalho. 
Dessa forma, pelo conceito ou pela política, a TV Câmara não existe só por questões logísticas e para proporcionar imagens que são distribuídas e acessadas por outros veículos de comunicação. Há também necessidade de os profissionais, com conhecimentos técnicos, editarem e encontrarem maneiras de empacotar os conteúdos para que o público tenha ainda mais condições de compreender o trabalho parlamentar e os esforços ligados a representantes e representados. Para isso, é essencial o documento de referência. Mas, além disso, manuais também, com amparo normativo, podem ser úteis, estabelecendo parâmetros que assegurem que os trabalhos sejam desenvolvidos, e a TV seja propriedade de todos os brasileiros.

A Internet também tem dado alguns nós importantes para reflexões que envolvem transmissões simultâneas e mais participação na condução dos veículos de comunicação. Para isso, as parcerias acadêmicas são essenciais. As universidades podem contribuir ainda mais para a realização desse trabalho de produção de referenciais. Com isso, há mais condições de fortalecer a rede legislativa de rádio e TV, frisando a necessidade de mais laços com as experiências nacionais, estaduais e municipais.

E, ao fim e ao cabo, destaco a missão da TV Câmara. Trata-se de uma TV pública que tem obrigações com a cidadania e a valorização do País, com a difusão de valores éticos, morais, sociais, artísticos e culturais do Brasil. Temas como a democracia, a defesa do consumidor, a proteção ao meio ambiente e o respeito aos direitos do cidadão são mais que um slogan; constituem o compromisso da TV Câmara, como todos nós podemos perceber, em oferecer alternativa de boa programação para os brasileiros. A TV Câmara é uma emissora que, orgulhosamente, não abaixa o microfone quando surgem opiniões divergentes.

Artigo recebido em: 30/07/2018

Artigo aceito para publicação em: 30/09/2018 